\title{
NGHIÊN CÚU ẢNH HƯỞNG HỆ THỐNG ĐẦU THU VNREDSAT-1 VÀ MÔI TRƯỜNG KHÍ QUYỂN TỚI KẾT QUẢ XỦ̉ LÝ BỨC XẠ ẢNH
}

\author{
LÊ DANH CƯỜNG(1), NGUYẼN VĂN BìNH(1), LƯO'NG NGUYẼ̃N HOÀNG HOA(1), \\ ĐINH XUÂN TRƯỜNG ${ }^{(1)}$, TRẦN NGỌC TƯỚNG ${ }^{(2)}$, LƯO'NG CHÍNH KÉ(3) \\ ${ }^{(1)} B o ̣ ̂ ~ C o ̂ n g ~ a n, ~\left({ }^{(2)} C u ̣ c\right.$ Viễn thám Quốc gia, ${ }^{(3)} H$ ội Trắc địa, Bản đồ, Viễn thám Việt Nam
}

\section{Tóm tắt:}

Biến đổi bức xạ ảnh mà đầu thu ảnh vệ tinh quang học ghi nhận được từ trị $D N$ về ảnh bức xạ phản xạ bề mặt đất giống như thực tế ngoài thực địa là vấn đề rất phức tạp. Trước hết cần kể đến ảnh hưởng của hệ thống ghi nhận ảnh của đầu thu và tiếp theo là ảnh hưởng của môi trường khí quyển. Ảnh hưởng hệ thống ghi nhận ảnh được nhà cung cấp ảnh đưa ra, thông qua hai tham số kiểm định Gain và Offset (Bias) trong tệp siêu dữ liệu (header file) của ảnh. Từ đó, chúng ta biến đổi ảnh $D N$ về ảnh bức xạ ở đỉnh khí quyển (hay ảnh bức xạ trước đầu thu). Bước tiếp theo, chúng ta cần loại bỏ ảnh hưởng của môi trường khí quyển tới bức xạ ảnh để nhận được ảnh phản xạ ở bề mặt đất của đối tượng. Phương pháp DOS (Dark Object Substraction) được coi là phương pháp rất thực tế vì không đòi hỏi các tham số về khí quyển, mà chỉ cần trích xuất một số thông tin từ ảnh có trong tệp siêu dữ liệu. Trong nghiên cứu của chúng tôi sử dụng ảnh vệ tinh VNREDSAT-1. Kết quả thực nghiệm cho thấy sản phẩm NDVI được tạo ra từ ảnh phản xạ bề mặt (Rosurf) đảm bảo tính trung thực hơn so với ảnh NDVI được tạo ra từ ảnh gốc DN, hay từ ảnh bức xạ ở đỉnh khí quyển $R$, hoặc từ ảnh phản xạ ở đỉnh khí quyển (Ro-toa). Điều này phù hợp với các nghiên cứu trên thế giới.

\section{1. Đặt vấn đề}

Tín hiệu phản xạ bề mặt đối tượng mà hệ thống đầu thu ghi nhận được, sau khi lượng tử hóa theo cấp số nhân có cơ số bằng 2 ( $2^{p}, p$ là số bit) sẽ cho ảnh gốc số $D N$ (Digital Number). Trị số DN không chỉ mang thông tin về bức xạ thông qua phản xạ bề mặt đối tượng mà còn chịu ảnh hưởng các tín hiệu nhiễu của bản thân hệ thống đầu thu ảnh và của môi trường khí quyển. Vì vậy để nhận được tín hiệu thực phản xạ bề mặt đối tượng, cần loại bỏ trước tiên ảnh hưởng của hệ thống đầu thu ảnh và của môi trường khí quyển trong quá trình xử lý ảnh.

Hiệu chỉnh bức xạ ảnh vệ tinh quang học về bản chất là loại bỏ những tín hiệu nhiễ் (sai số) trong quá trình thu nhận ảnh. Giả sử rằng những sai số trong như sai số của các

Ngày nhận bài: 04/3/2016 tế bào $C C D$ và sai số méo hình hệ thống quang học kính viễn vọng cuả đầu thu đã được xử lý (ảnh mức 1A), sau đó ảnh hưởng sai số ngoài do độ cong và góc quay của Trái Đất tiếp tục được xử lý (ảnh mức 1B). Sau khi ảnh mức $1 \mathrm{~B}$ được đưa về hệ quy chiếu WGS 84 với việc sử dụng DEM thô có độ phân giải $1 \mathrm{~km}$, chúng ta nhận được ảnh mức $2 \mathrm{~A}$. Vấn đề tiếp tục cần được xử lý để tạo ảnh có bức xạ phổ về bức xạ thực tế của đối tượng phản xạ ở bề mặt đất mà đầu thu thu nhận được. Để giải quyết vấn đề này cần thiết tiến hành hai nội dung chính:

+ Hiệu chỉnh bức xạ ảnh theo tham số kiểm định của đầu thu. Về thực chất là sử dụng các tham số kiểm định của đầu thu được kiểm định trên quỹ đạo vệ tinh. Các tham số này là hai giá trị Gain và Offset (hay

Ngày chấp nhận đăng: 14/3/2016 
bias) của đầu thu từ hàm tương quan bức xạ của đầu thu với giá trị bức xạ thực của đối tượng ở bãi kiểm định (hay thiết bị kiểm định bức xạ đầu thu đặt trên vệ tinh) được đo khi vệ tinh bay qua quét ảnh.

+ Hiệu chỉnh bức xạ ảnh do ảnh hưởng môi trường khí quyển. Bức xạ phản xạ từ đối tượng hay bức xạ Mặt Trời đi tới đối tượng trên bề mặt đất đều bị hấp thụ hay tán xạ; ngoài ra còn chịu một lượng ánh sáng bức xạ do hiện tượng khuyếch tán ánh sáng bầu trời. Trong số những yếu tố của khí quyển tác động tới truyền dẫn bức xạ ánh sáng đáng kể là: hơi nước, hỗn hợp khí, sol-khí. Chúng ta có thể chia ra làm 2 nhóm hiệu chỉnh:

Hiệu chỉnh tuyệt đối sử dụng tham số vật lý khí quyển;

Hiệu chỉnh tương đối sử dụng các tham số của ảnh.

Nhóm phương pháp sử dụng tham số vật lý khí quyển tiêu biểu là phương pháp $6 \mathrm{~S}$ dựa trên lý thuyết truyền bức xạ trong khí quyển $[3,6]$. Các tham số vật lý khí quyển có liên quan tới hai hiện tượng là hiện tượng tán xạ và hiện tượng hấp thụ của một số thành phần trong khí quyển như: ôzôn, ô$x y$, dioxit cac-bon, hỗn hợp khí và sol-khí [4, $7,8]$. Các tham số đầu vào cho mô hình $6 \mathrm{~S}$ bao gồm: hình học quan hệ giữa mặt trời trái đất - đầu thu, mô hình khí quyển (mô hình khí quyển quốc tế, hoặc mô hình khí quyển của Mỹ 1962 và 1976) cho các thành phần khí, mô hình sol-khí (loại và hàm lượng sol-khí), giá trị phản xạ đo ngoài thực địa và đo trên các ảnh kênh phổ. Mô hình 6S đòi hỏi một số số liệu đo thực địa về tính chất quang học khí quyển ở thời điểm thu nhận ảnh. Đây cũng chính là nhược điểm chính của phương pháp, mặc dù phương pháp cho độ chính xác cao.

Ở nhiều trường hợp thực tế, việc tiếp cận các tham số khí quyển không dễ dàng, cho nên nhóm phương pháp sử dụng các tham số của ảnh từ tệp siêu dữ liệu (header file) là giải pháp thiết thực, cho phép hiệu chỉnh ảnh hưởng khí quyển với độ chính xác nằm trong giới hạn cho phép. Một phiên bản đơn giản của phương pháp chỉ sử dụng thông tin ảnh là phương pháp "trừ đối tượng tối" DOS (Dark Object Substraction) [1, 2], đã được sử dụng trong nhiều ứng dụng thực tiễn. Phương pháp DOS cho phép trích xuất thông tin bức xạ tán xạ khí quyển bằng cách sử dụng đối tượng tối nhất trong cảnh ảnh. Trong phương pháp DOS đại lượng bức xạ tán xạ khí quyển là thông số đầu vào quan trọng để giải phương trình DOS nhằm tính phản xạ bề mặt đối tượng trên mặt đất. Đại lượng bức xạ tán xạ khí quyển được ước lượng từ dữ liệu ảnh bằng cách sử dụng cận dưới của biểu đồ ảnh cho mỗi kênh ảnh. Vùng giới hạn tương đối thấp của biểu đồ ("đối tượng tối") được coi là biểu hiện của lượng bức xạ tán xạ khí quyển trong kênh ảnh đó. Phản xạ bề mặt của đối tượng tối được giả định bằng $1 \%$ cho các cảnh ảnh ở dải phổ nhìn thấy [5]. Do vậy, bức xạ tán xạ khí quyển được tính bằng bức xạ của "đối tượng tối" trừ đi bức xạ tham gia của $1 \%$ phản xạ bề mặt.

Bài báo trình bầy kết quả nghiên cứu ảnh hưởng của hệ thống đầu thu và của môi trường khí quyển tới bức xạ ảnh VNREDSAT-1. Sau khi loại bỏ (hiệu chỉnh) ảnh hưởng của hệ thống đầu thu và của môi trường khí quyển tới bức xạ ảnh, chúng ta nhận được ảnh phản xạ bề mặt. Sản phẩm lớp cao - chỉ số thực vật NDVI được tạo ra từ ảnh phản xạ bề mặt sẽ đảm bảo tính trung thực của bề mặt địa hình, so với ảnh khi chưa được hiệu chỉnh.

\section{Cơ sở khoa học}

\subsection{Hàm bức xạ ảnh}

Hình 1 giới thiệu những tia sáng Mặt trời đi trong khoảng không vũ tru mang năng lượng Eo đến đỉnh khí quyển. Sau đó đi vào bầu khí quyển một phần tia sáng bị khuyếch 
tán mang năng lượng $E d$, một phần năng lượng ánh sáng $E b$ đi tới đối tượng mà chúng ta quan tâm khảo sát. Tia sáng đi tới mang năng lượng $E b$ hợp với phương thiên đỉnh một góc $\theta 0$, sau đó phản xạ đi về đầu thu Ls. Tia Ls hợp với phương thiên đỉnh một góc $\theta$. Tia sáng $L p$ đi về đầu thu là tia tán xạ trong bầu khí quyển. Tia Lp phản ảnh trạng thái chất lượng của môi trường khí quyển thông qua độ dày quang học solkhí. Tương tự tia sáng $\mathrm{m}$ bị tán xạ nhiều lần trong khí quyển cũng đi về đầu thu. Ngoài ra tia a là tia phản xạ từ đối tượng bên cạnh bị tán xạ trong khí quyển rồi đi về đầu thu. Trong số các tia sáng đi về đầu thu chỉ có tia Ls mang thông tin về đối tượng mà chúng ta quan tâm. (xem hình 1)

Coi địa hình là địa hình đồng nhất Lambert, bức xạ mà đầu thu ghi nhận được ứng với bước sóng $\lambda$ là $\operatorname{Lt}(\lambda)$ sẽ là tổng của 2 thành phần:

- Thành phần bức xạ tán xạ chùm tia Mặt Trời bởi khí quyển, $\operatorname{Lp}(\lambda)$.

- Thành phần bức xạ phản xạ bởi bề mặt đất, $\operatorname{Ls}(\lambda)$. Nghĩa là:

$$
\operatorname{Lt}(\lambda)=\operatorname{Lp}(\lambda)+\operatorname{Ls}(\lambda)
$$

Các tín hiệu bề mặt (đất) được hệ thống tạo ảnh ghi nhận nhờ các tế bào quang điện đặt ở bề mặt của đầu thu. Giả thuyết là các đặc tính của hệ thống quang học đã biết trước, sao cho có thể phát hiện bức xạ từ tín hiệu thông qua hàm của đầu thu. Với cửa mở của ống kính quang học đầu thu tương đối nhỏ, bức xạ đầu thu sẽ là tích của bức xạ phản xạ từ đối tượng và góc khối của cửa mở ống kính đầu thu $\delta \omega$. Bức xạ tới đầu thu sẽ là tổng của bức xạ phản xạ từ đối tượng và bức xạ của khí quyển. Phương trình tổng quát tạo ảnh có dạng:

$E_{i}\left(\mathrm{x}_{\mathrm{i}}, y_{i}\right)=$

$$
\left[L_{t}\left(\vec{r}_{t}, \vec{r}_{m}\right) T_{u}\left(\vec{r}_{t}, \vec{r}_{m}\right)+L_{p}\left(\vec{r}_{t}, \vec{r}_{m}\right)\right] d \omega
$$

Trong đó: $\mathrm{E}_{\mathrm{i}}$ - Bức xạ đầu thu có tọa độ ảnh $\left(\mathrm{x}_{\mathrm{i}}, \mathrm{y}_{\mathrm{i}}\right)$;

$L_{t}\left(\vec{r}_{t}, \vec{r}_{m}\right)$ - Bức xạ của phần tử bề mặt (đất) trên ảnh theo hướng từ mặt đất về đầu thu; $L_{u}\left(\vec{r}_{t}, \vec{r}_{m}\right)$ - Hệ số truyền dẫn bức xạ của khí quyển theo hướng từ mục tiêu về đầu thu; $L_{p}\left(\vec{r}_{t}, \vec{r}_{m}\right)$ - Bức xạ tán xạ khí quyển giữa mục tiêu (trên bề mặt đất) và đầu thu;

㺟 - Vị trí của đối tượng (mục tiêu) trong hệ tọa độ toàn cầu;

$\vec{F}_{\mathrm{s}} \quad-$ Vị trí của đầu thu trong hệ thống tọa

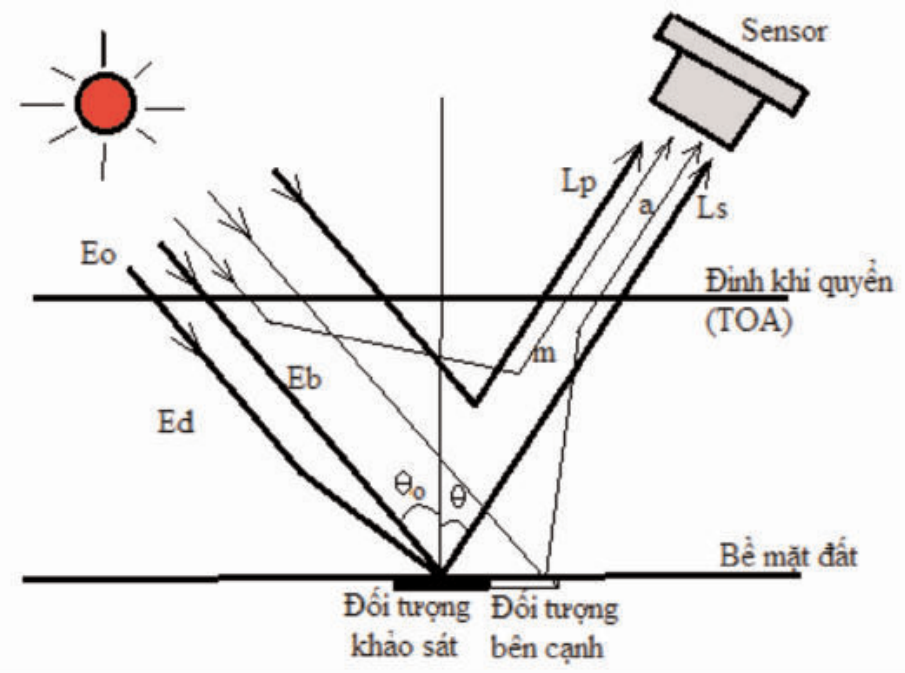

Hình 1: Quan hệ hình học Mặt Trời - Mặt Đất - Đầu thu thông qua các tia sáng 
độ toàn cầu;

$d \omega$ - Góc khối cửa mở đầu thu.

Phương trình (1) chỉ biểu diễn cường độ bức xạ mà bỏ qua hiện tượng phân cực.

Nếu lập tỉ số $E_{i}\left(x_{i}, y_{i}\right) / \delta \omega$ thì phương trình (1) sẽ có dạng (2) và gọi là bức xạ đầu thu:

$$
\begin{aligned}
& \frac{E_{i}\left(x_{i}, y_{i}\right)}{d \omega} \equiv L_{m}\left(\vec{r}_{t}, \vec{r}_{m}\right)= \\
& =L_{t}\left(\vec{r}_{t}, \vec{r}_{m}\right) T_{u}\left(\vec{r}_{t}, \vec{r}_{m}\right)+L_{p}\left(\vec{r}_{t}, \vec{r}_{m}\right)
\end{aligned}
$$

Mục tiêu của chúng ta là biến đổi phương trình (2) để nhận được phản xạ bề mặt đối tượng với sự tham gia của bức xạ đầu thu. Do đó phương trình tổng quát (2) cần được đơn giản hóa trong ứng dụng thực tế, với các giả thuyết sau:

+ Thứ nhất: khí quyển được coi là đồng nhất về khối lượng không khí và ở mặt phẳng nằm ngang song song với bề mặt đất. Sự thay đổi tính chất khí quyển chỉ theo phương thẳng đứng (hướng $\mathrm{z}$ ). Các thành phần không khí đặc biệt khác như nêu trên coi như bỏ qua, cũng như bỏ qua trường hợp trời có mây.

+ Thứ hai: Bề mặt đối tượng được chiếu sáng:

Từ Mặt Trời với bức xạ ở đỉnh khí quyển là $\mathrm{E}_{\mathrm{O}}$; các tia tới tạo với phương thiên đỉnh góc $\theta_{S}$

Bầu trời có hình bán cầu đồng nhất. Bỏ qua ảnh hưởng từ phản xạ của các đối tượng bên cạnh.

+ Thứ ba: Sự phân bố bức xạ bầu trời được thay thế bằng các thành phần tương ưng đồng nhất. Giả thuyết này cho phép biểu diễn bức xạ bầu trời trên bề mặt đối tượng không nằm ở mặt phẳng nằm ngang, do đó nó chỉ nhìn thấy một phần bầu trời.

+ Thứ tư: Bề mặt đất giả thuyết là bề mặt tuân theo định luật Lambert có albedo biến thiên từ điểm này sang điểm khác. Bức xạ của bề mặt Lambert là độc lập đối với góc quan trắc và chỉ phụ thuộc vào bức xạ toàn phần và albedo bề mặt (phản xạ nhị bàn ğ cầu).

Với bốn giả thuyết nêu trên, phương trình (2) sau khi thực hiện các phép biến đổi sẽ có dạng cuối cùng:

$$
A\left(x_{t}, y_{t}\right)=\frac{\pi\left[L_{m}\left(x_{t}, y_{t}\right)-L_{p}(z)\right]}{T_{u}(z)\left[E_{o} T_{d}(z) \cos \theta_{s}+E_{\mathrm{S}}(z)\right]}
$$

Trong đó: $A\left(x_{t}, y_{t}\right)$ - Albedo bề mặt của đối tượng tại điểm $\left(x_{t}, y_{t}\right)$;

$L_{m}\left(x_{t}, y_{t}\right)$ - Bức xạ đầu thu liên quan đến đối tượng $\vec{r}_{t}\left(x_{t}, y_{t}\right)$;

$T_{u}(z)$ - Tham số truyền dẫn bức xạ ở độ cao $z$ đến đầu thu;

$\mathrm{E}_{\mathrm{O}}$ - Bức xạ mặt trời ở đỉnh khí quyển ứng với bước sóng $\lambda$;

$T_{d}(z)$ - Tham số truyền dẫn bức xạ từ mặt trời đến độ cao z;

$\mathrm{E}_{\mathrm{s}}(\mathrm{z})$ - Bức xạ bầu trời trên bề mặt nằm ngay ở độ cao z;

$L_{p}(z)$ - Bức xạ khí quyển giữa đầu thu và bề mặt đối tượng ở độ cao z;

$\theta_{S}$ - Góc thiên đỉnh mặt trời.

Phương trình (3) biểu diễn mô hình phản xạ bề mặt của đối tượng. Phương pháp DOS hiệu chỉnh ảnh hưởng của khí quyển tới bức xạ ảnh được thực hiện dựa trên mô hình (3).

\subsection{Các mức xử lý bức xạ ảnh}

Khí quyển là môi trường viễn thám rất phức tạp, gây ra những tín hiệu nhiễu (sai số), ảnh hưởng tới tín hiệu thực về đối tượng trên ảnh. Nguyên lý trong đo đạc nói chung, trong xử lý tín hiệu số nói riêng là cần loại bỏ những tín hiệu nhiễu; sau đó các bước xử lý tiếp theo mới đảm bảo độ tin cậy. Thậm chí ở ngoài biển tín hiệu phản xạ phổ từ bề mặt biển chỉ vào khỏang từ 5- 
$20 \%$, còn lại là các tín hiệu nhiễu.

Tư liệu ảnh vệ tinh mà các nhà phân phối ảnh cung cấp cho người sử dụng thường được xử lý ở các mức (level) khác nhau, theo nhu cầu sử dụng của khách hàng. Mức xử lý càng tinh thì giá thành càng cao. Nhằm giảm giá thành tư liệu mua ảnh, người sử dụng làm chủ công nghệ xử lý ảnh, có thể đặt ảnh ở mức xử lý $1 \mathrm{~A}$ hay $2 \mathrm{~A}$, sau đó tiến hành xử lý ở các mức cao hơn.

Bức xạ phổ ảnh vệ tinh quang học nói chung, của ảnh VNREDSat-1 nói riêng có thể khái quát ở 4 mức xử lý thường gặp như sau: (xem hinh 2)

Ảnh số 1 - ảnh bức xạ sau đầu thu. Đây là ảnh bức xạ gốc $D N$ có thể ở mức $1 \mathrm{~A}$, hay $2 \mathrm{~A}$, đơn vị là $\left(\mathrm{W} /\left(\mathrm{mm}^{2}\right.\right.$.ste. $\left.\left.\mu \mathrm{m}\right)\right)$. Mức xử lý $1 \mathrm{~A}$ mới chỉ được hiệu chỉnh bức xạ phổ do sai số méo hình hệ thống quang học của đầu thu và hiệu chỉnh sự khác biệt về độ nhậy phổ của các tế bào quang điện (detectors). Mức $1 \mathrm{~A}$ thường cung cấp cho người sử dụng có khả năng tự xử lý hình học ảnh. Ảnh mức $2 \mathrm{~A}$ có mức xử lý hình học về lưới chiếu WGS84 theo mặc định, không sử dụng điểm khống chế thực địa, nhưng sử dụng DEM thô có độ phân giải $1 \mathrm{~km}$ (sau khi hiệu chỉnh biến dạng toàn cảnh, ảnh hưởng góc quay, độ cong của quả đất và biến động độ cao quỹ đạo vệ tinh - đây là mức xử lý 1B); còn mức xử lý phổ mức $2 \mathrm{~A}$ giống như mức $1 \mathrm{~A}$, nhưng được tái mẫu (resampling) sau khi xử lý hình học ảnh.

Ảnh số 2 - ảnh bức xạ trước đầu thu (atsensor radiance image) hay ảnh bức xạ ở đỉnh khí quyển là ảnh được hiệu chỉnh các thông số Gain và Offset của đầu thu từ ảnh bức xạ sau đầu thu. Ảnh có đơn vị là $\left(\mathrm{W} /\left(\mathrm{mm}^{2}\right.\right.$.ste. $\left.\left.\mu \mathrm{m}\right)\right)$.

Ảnh số 3 - ảnh phản xạ trước đầu thu

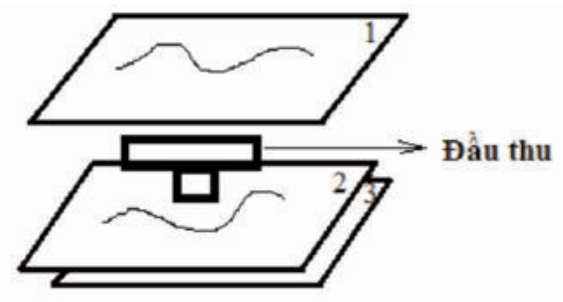

Đình khí quyển

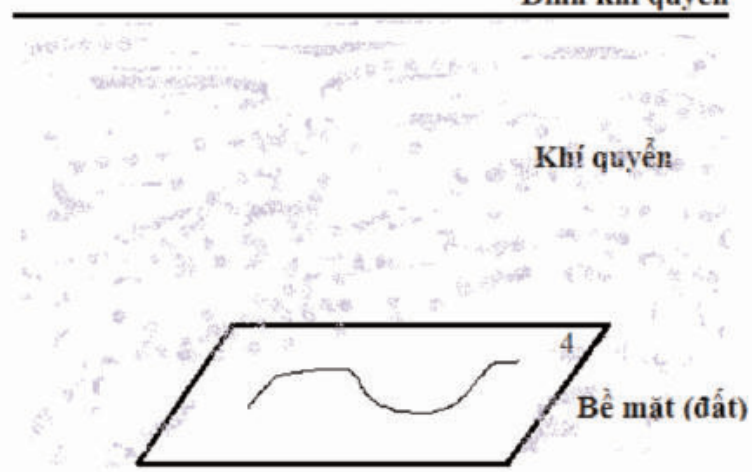

Hình 2: Mô phỏng 4 mức xử lý bức xạ phổ của ảnh:

1 - ảnh bức xạ sau đầu thu $D N$ (ảnh gốc),

2 - ảnh bức xạ trước đầu thu hay ảnh bức xạ ở đỉnh khí quyển,

3 - ảnh phản xạ trước đầu thu hay ảnh phản xạ ở đỉnh khí quyển,

4 - Ảnh phản xạ bề mặt (đất) 
hay ảnh phản xạ ở đỉnh khí quyển. Đây là ảnh đã được hiệu chỉnh từ ảnh bức xạ trước đầu thu do ảnh hưởng của góc cao Mặt Trời, khoảng cách thiên văn tương hỗ giữa Mặt Trời và Trái Đất, và năng lượng bức xạ Mặt Trời ở đỉnh khí quyển $\mathrm{E}_{\mathrm{O} \lambda}$ tương ứng với bước sóng $\lambda$ của từng kênh ảnh.

Ảnh số 4 - ảnh phản xạ bề mặt. Ảnh được hiệu chỉnh ảnh hưởng của khí quyển từ ảnh bức xạ trước đầu thu hay từ ảnh phản xạ trước đầu thu (phụ thuộc vào phương pháp hiệu chỉnh khí quyển) về ảnh phản xạ ở bề mặt đất.

\subsection{Quy trình công nghệ tổng quát xử} lý bức xạ ảnh do ảnh hưởng của khí quyển

Phương pháp hiệu chỉnh tuyệt đối bức xạ ảnh (phương pháp 6S) tuy sát với thực tế khách quan nhưng lại nảy sinh sự bất lợi trong ứng dụng thực tế, vì đòi hỏi các đại lượng đo vật lý khí quyển, đặc biệt gặp khó khăn khi sử dụng các ảnh vệ tinh cũ. Vì vậy, các nghiên cứu hướng tới:

- Hạn chế sử dụng tham số khí quyển;

- Dễ dàng tiện dụng khi ứng dụng tư liệu viễn thám;

- Phát huy tối đa những thông tin chiết xuất từ Header file của ảnh;

- Tách biệt và hiệu chỉnh ảnh hưởng yếu tố địa hình bề mặt;

- Đảm bảo độ chính xác hiệu chỉnh khí quyển áp dụng trong thực tiễn.

Phương pháp DOS được coi là giải pháp hiệu dụng, đảm bảo yêu cầu về độ chính xác hiệu chỉnh bức xạ ảnh và tăng khả năng ứng dụng thực tế. Cho nên nội dung của quy trình công nghệ được thành lập cho mô hình DOS. Sơ đồ quy trình công nghệ hiệu chỉnh bức xạ ảnh vệ tinh từ ảnh gốc có giá trị $\mathrm{DN}$ về ảnh bức xạ trước đầu thu $\mathrm{R}$ (hay L), sau đó về ảnh phản xạ ở đỉnh khí quyển và phản xạ bề mặt đất được mô tả trên hình
3.

Đầu vào trong quy trình công nghệ là tư liệu ảnh gốc $D N$ mức xử lý $2 A$ và tệp siêu dữ liệu (Header file). Các trị số DN của các pixel ảnh phản ánh cấp độ xám quang học của đối tượng. Ảnh gốc (ảnh thô) - ảnh DN đã được loại bỏ sai số trong, bao gồm các sai số hệ thống, như sai số hệ thống méo hình quang học của đầu thu (sai số méo hình), sai số của các tế bào cảm biến; và giữ nguyên chất lượng bức xạ của ảnh. Đây là dữ liệu đầu vào để biến đổi về ảnh bức xạ trước đầu thu.

\section{Thực nghiệm trên ảnh VNREDSat-1}

Vệ tinh VNRDSat-1 là vệ tinh quang học thuộc loại vệ tinh nhỏ. Hệ thống quang học thiết bị đầu thu có ống kính viễn vọng Korsch với độ dài tiêu cụ $5131 \mathrm{~mm}$, cửa mở tương đối bằng $F / 16$. Đầu thu ảnh vệ tinh VNREDSat-1 làm việc trên vệ tinh theo nguyên lý chổi đẩy (pushbroom). Tế bào cảm quang (CCD) tiếp nhận bức xạ phản xạ từ đối tượng được bố trí theo mảng và được đặt ở mặt phẳng tiêu cự của hệ thống quang học. Hàm phản ánh phổ đầu thu VNREDSat-1 phản ánh độ nhậy 5 kênh ảnh (Pan, NIR, R, G, B của đầu thu NAOMI được giới thiệu trên trang Web (www.vnredsat-1). Đầu thu trên VNREDSat -1 tương tự như đầu thu AISat-2 của Algeria (www.alsat2). Để thấy rõ ảnh hưởng hệ thống ghi nhận ảnh của đầu thu VNREDSat-1, cũng như của khí quyển tới bức xạ của cảnh ảnh, phần thực nghiệm được tiến hành trên tư liệu ảnh VNREDSat-1. (xem hình3)

\subsection{Tư liệu ảnh}

Ảnh VNREDSat-1 thu nhận ngày 18/04/2015 của TP Hồ Chí Minh có các kênh Pan và MS ở mức $2 \mathrm{~A}$. Cho mục đích thực nghiêm, các kênh MS được cắt với có kích thước $500 \times 500$ pixels. Ảnh Pan cắt có kích thước $2000 \times 2000$ pixels. Các tham số thống kê tương ứng của ảnh cắt Pan, $R, G$, $B$ được ghi chú bên dưới ảnh. Dữ liệu ảnh 


\section{Nghiên cúu - Úng dụng}

được minh họa trên. (xem hình 4)

Tham số Gain và Bias của đầu thu cho từng kênh ảnh lấy từ sản phẩm DIMAP của VNREDSAT-1, được trích lục dưới đây (xem hinh 5).
Để xử lý bức xạ phổ bề mặt, các tham số về vị trí tương hỗ giữa Mặt Trời-Mặt ĐấtĐầu thu cho các kênh ảnh MS và Pan của cảnh ảnh được trích lục từ header file trên. (Xem hinh 6).

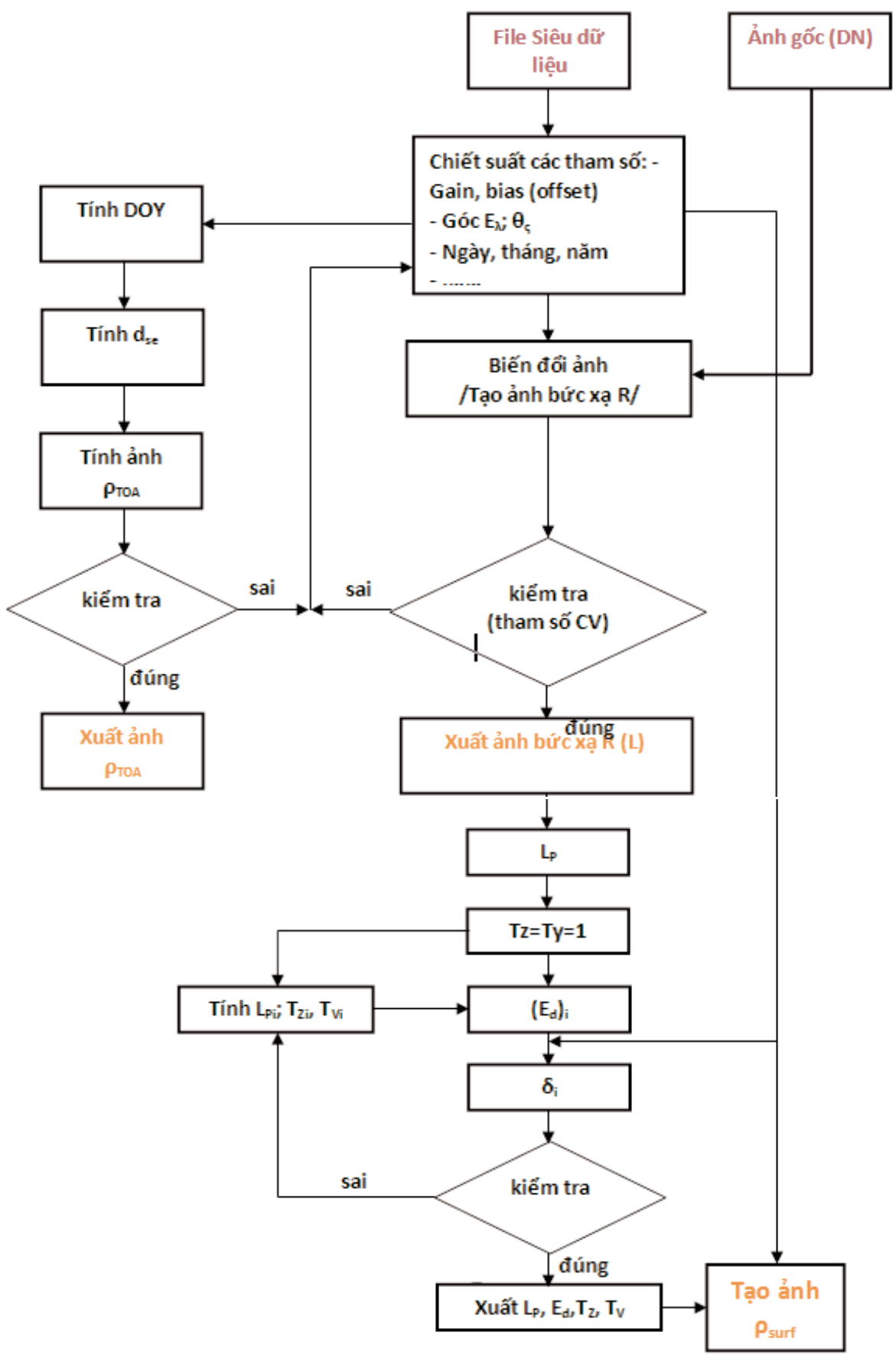

Hình 3: Sơ đồ quy trình công nghệ hiệu chỉnh bức xạ ảnh vệ tinh quang học 

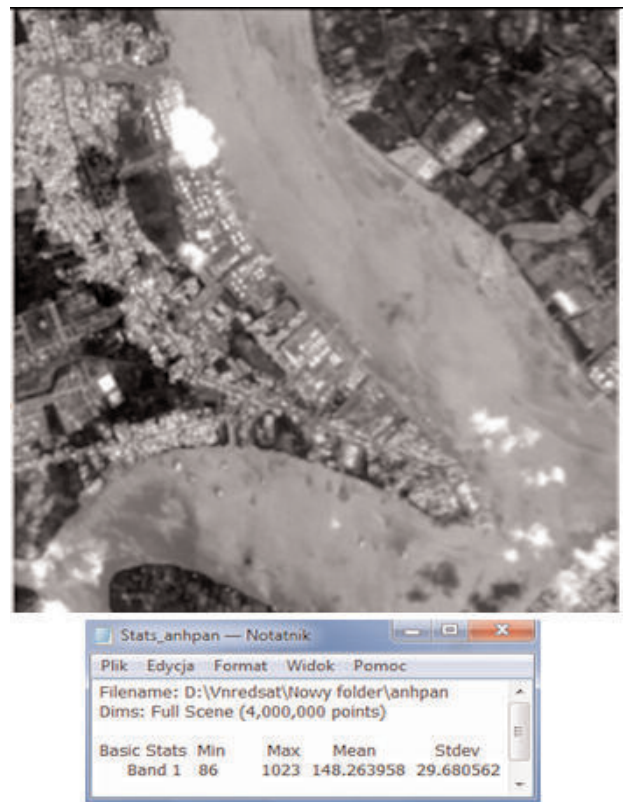

Ảnh Pan gốc múc $2 A$

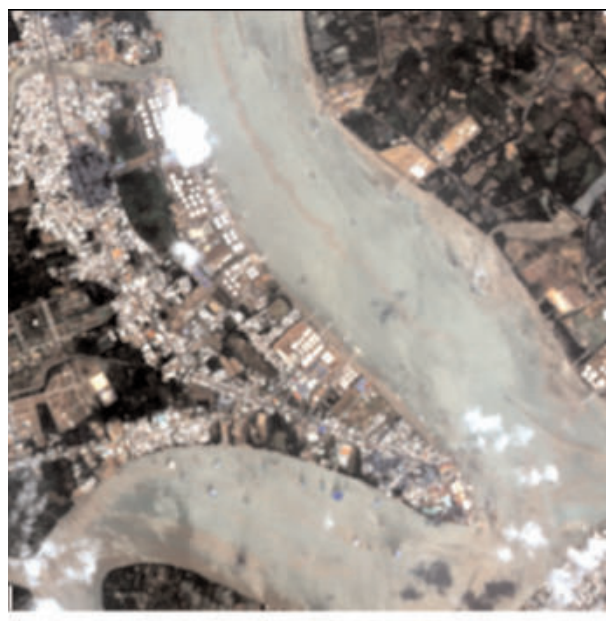

Basic Stats Min Max Mean Stdev $\begin{array}{lllll}\text { Band } 1 & 73 & 406 & 130.425532 & 30.555528\end{array}$

$\begin{array}{lllll}\text { Band } 2 \quad 98 \quad 435 \quad 142.336844 & 24.500958\end{array}$

$\begin{array}{lllll}\text { Band } 3 & 121 & 351 & 155.189376 & 19.738927\end{array}$

Hình 4: Ảnh gốc Pan và MS mức 2A VNREDSat-1 làm thực nghiệm VNREDSAT-1 DIMAP product data-sheet

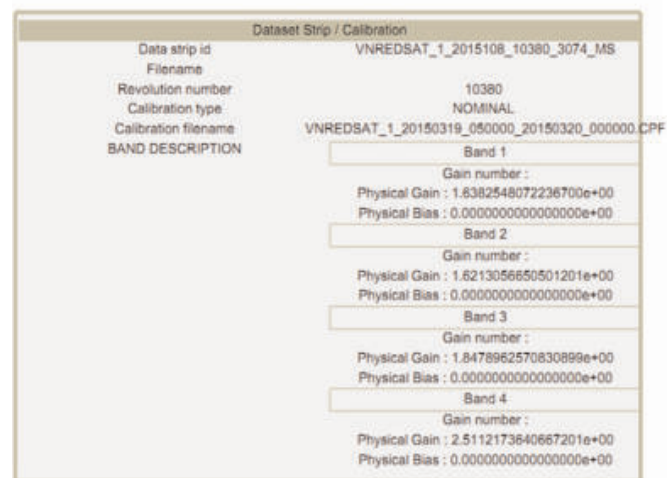

\section{VNREDSAT-1 DIMAP product data-sheet}

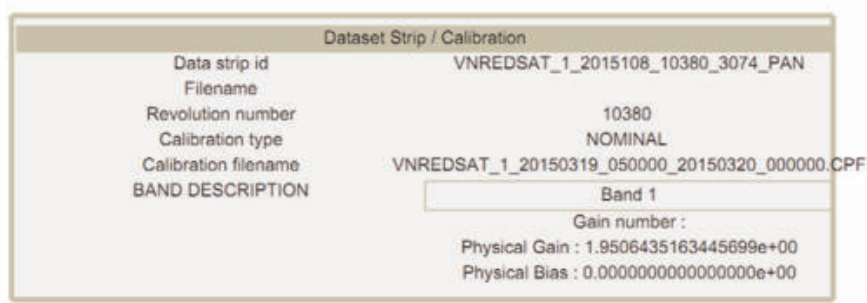

Hình 5: Sản phẩm DIMAP về Gain và Bias của các kênh MS và PAN VNREDSat-1

\begin{tabular}{|c|c|}
\hline & Dataset sources \\
\hline \multicolumn{2}{|c|}{ SCENE VT M 2015-04-18 03:46:29.3805480 } \\
\hline la & SCENE VI M 2015-04-18 03:46:29.380548 0 \\
\hline \multicolumn{2}{|r|}{ 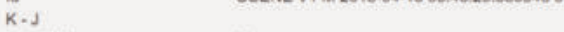 } \\
\hline Line shin & 0 \\
\hline Date & 2015-04-18 \\
\hline Time & $03: 46: 29 \cdot 380548$ \\
\hline instrument & NAOMII \\
\hline Sensor & MS \\
\hline Satelite incidence angle & 28.177203 \\
\hline Satelinte azimuth angle & 235.289869 \\
\hline Viewing angle along track & -19.051092 \\
\hline Viewing angle across track & 17.747244 \\
\hline Sun azimuth & 90.501369 \\
\hline Sun elevation & 73.675593 \\
\hline
\end{tabular}

\begin{tabular}{|l|l|}
\hline \multicolumn{1}{|c|}{ Dataset sources } \\
\hline SCENE V1 P 2015-04-18 03:46:29.440972 0 \\
\hline Id & SCENE Vi P 2015-04-18 03:46:29.440972 0 \\
\hline K-J & \\
Line shift & 0 \\
Date & $2015-04-18$ \\
Time & $03: 46: 29.440972$ \\
\hline Instrument & NAOM11 \\
Sensor & PAN \\
Satellite incidence angle & 28.201800 \\
Satellite azimuth angle & 235.238418 \\
Viewing angle along track & -19.083132 \\
Viewing angle across track & 17.747388 \\
Sun azimuth & 90.502138 \\
Sun elevation & 73.675708 \\
\hline
\end{tabular}

Hình 6: Sản phẩm DIMAP về tham số hình học của các kênh MS và Pan VNREDSat-1

Xem tiếp số 28 - 6/2016 